ISCKMC 2020

International Scientific Congress «KNOWLEDGE, MAN AND CIVILIZATION»

\title{
AUGMENTED REALITY TECHNOLOGY CONTRIBUTING TO THE DEVELOPMENT OF STUDENTS' DIGITAL SKILLS
}

\author{
Svetlana Innokentievna Desnenko (a)*, Tatyana Evgenievna Pakhomova (b), \\ Svetlana Efimovna Starostina (c), Alena Dmitrievna Fedotova (d) \\ *Corresponding author
}

(a) Transbaikal State University, 30, Aleksandro-Zavodskaya st., Chita, Russia, desnenkochita@rambler.ru, (b) Chita Pedagogical College, 51a, Krasnoy Zvezdi st., Chita, Russia, masskva_te@mail.ru, (c) Transbaikal State University, 30, Aleksandro-Zavodskaya st., Chita, Russia, sestarost@mail.ru, (d) Transbaikal State University, 30, Aleksandro-Zavodskaya st., einclub@mail.ru

\begin{abstract}
Global digital transformation of the education system currently taking place in Russia brings forth the issue of employing digital technologies to develop digital skills in future teachers. The study aims to provide a rationale for using augmented reality (AR) technology in the learning process to shape digital literacy and its integral digital skills in future teachers. The paper reveals three groups of digital skills (basic, general and specialized professional) that make up digital literacy. The paper provides a detailed description of AR technology, types of AR training applications, and advantages and disadvantages of using AR to facilitate the learning process. The study relies on the following general research methods, namely: comprehensive comparative analysis, scientific reflection, analysis of literature on the research problem, and analysis of authors' personal pedagogical and scientific activities. The paper presents the results of a study conducted at Transbaikal State University and Chita Pedagogical College. The authors outline a list of digital skills that can be formed based on AR technology. The paper suggests that with digital learning technology the teacher should invoke the learning outcomes and determine the level at which basic, general and specialized professional digital skills should be developed in students as future teachers. It is the learning outcomes that will guide the choice of digital technologies and, as a special case, the choice of AR technology.
\end{abstract}

2357-1330 @ 2021 Published by European Publisher.

Keywords: Augmented reality (AR) technology, digital skills, teacher 


\section{Introduction}

At present, the era of global informatization of society is being replaced by the era of digitalization, which implies the introduction of digital technologies into various spheres of human activity. Digital technologies further improve labor efficiency and allow for an individual approach in various areas (Desnenko \& Pakhomova 2020). According to some researchers, educationally significant digital technologies include telecommunication technologies, big data, artificial intelligence, virtual and augmented reality, electronic identification and authentication, cloud technologies, Internet of Things, blockchain technologies, professional social networks, etc. (Blinov et al., 2019; UNESCO, 2019). The use of digital technologies in education enables new prospects for setting up the learning process and solving a wide range of educational tasks (Petrova \& Bondareva, 2019).

\section{Problem Statement}

To benefit from digital technologies, a specialist needs digital literacy that is one of the key literacy in the $21^{\text {st }}$ century. According to the updated UNESCO ICT Competency Framework for Teachers. Version 3, digital literacy is referred to as the ability of an individual to use digital technologies, communications or networks to retrieve, evaluate, use and create information; comprehend and use information in multiple formats from a wide range of sources; effectively complete tasks in a digital environment (UNESCO, 2019). Many scientists note that digital literacy intricately involves digital skills viewed as vital dimensions of human activity in a digital society. Globally, tens of millions of jobs will emerge in the coming years, requiring professionals with a high level of comfort with digital technology. Such workforce, dealing with digital technology, can take advantage of even greater opportunities stemming from the constant advancement of digital technologies, platforms and devices (Digital Skills Toolkit, 2018).

Thus, the education system, including professional pedagogical that is currently "at a critical juncture, being tasked to train pedagogical personnel in the context of the development of digital technology", faces the most important challenge of training highly qualified teachers able to prepare students for life and work in a modern digital society (Abylkasymova et al., 2019). This entails the search for answers to the questions as to what a modern teacher should be like to implement his/her professional activity in the light of digitalization of education, what necessary digital skills he/she should possess.

\section{Research Questions}

The literature indicates that digital skills are referred to as well-established, "automated behaviors grounded on basic knowledge and skills in the use of digital devices, communication applications and networks to access and control information" (Voronina, 2019, p. 234). In the Working Group on Education: digital skills for life and work (UNESCO), digital skills that underlie digital literacy are divided into three groups: 1. Basic functional (core) digital skills aimed at the functional use of digital devices and applications, configuring settings and managing files, using keyboards and touch technologies, etc. 2. General digital skills involving the use of online applications and services, various 
software, digital content creation, the use of digital tools to solve problems, and in general the ability to work with information. 3. Specialized professional digital skills, the so-called "advanced" skills that are at the core of activities performed by an ICT specialist (programming, app development, communication network management, etc.). They function together with such "soft" skills as the ability to work in a team, creativity, critical thinking (UNESCO, 2017). A similar classification is discussed in the Digital Skills Toolkit (Digital Skills Toolkit, 2018), where digital skills are distributed by levels: basic, general and advanced.

The analysis of the literature showed that digital technologies based on virtual and augmented reality are most often used in training specialists, including future teachers, for the development of digital skills. Mobile technology is making a positive contribution to education, while augmented reality (AR), along with virtual reality (VR) and mixed reality (MR) are considered "key learning technologies for the next decade". Despite the positive results, issues related to the study and analysis of the experience of implementing AR by teachers and students, the creation of virtual content and 3D models have yet to be explored (Tzima et al., 2019).

The literature provides definitions of AR technology, which cover its various features. Augmented reality (AR) is a real-time environment that supplements the physical world, as we see it, with digital data using any devices - tablets, smartphones or others, and a software part (Zhigalova \& Tolstopyatov, 2019). Augmented reality is a fast-growing area of interactive design that seamlessly integrates virtual content with real-world scenes (Youm et al., 2019). AR applications involve control interfaces, simulators, programs for innovative learning. An enhanced usage of AR technology in the learning process is promoted by its features such as visibility, interactivity, visualization of material.

Today, the use of AR technology in educational practices is a promising area of research. The experience of using augmented reality is described by practitioners alone, who most often address the specific experience of using the technology and practically ignore its systematization. Some domestic authors offer suggestions for the classification of augmented reality. However, foreign sources give the classification of its application specifically in the educational sphere. The authors mention the following types of AR learning applications: books with AR technology, which form a kind of bridge between the physical and digital world; games; training applications; modeling objects; skill training apps (Yuen et al., 2011).

The literature on the issue of using AR technology in education elicited a number of advantages of this technology. They involve concentration of student's attention in the learning process, strengthening of motivation for learning, independence in studying educational content, formation of digital skills of the learner, personalization of training (individualized learning process), promotion of student's involvement in the learning process, more effective cognitive development. Along with the highlighted positive aspects of using AR in education, there is also a critical viewpoint on this technology being used in the educational process. Excessive enthusiasm for AR by students can distract them from studying the discipline as a whole. Other disadvantages involve an insufficient number of studies of this technology in the scientific environment, which does not respond to a number of questions related to its positive impact on learning; high cost of hardware and software to ensure complete implementation of this technology in education; the lack of a variety of software designed for the development of augmented reality. AR 
technology is developing rapidly, therefore, in the near future, some of the critical questions on the use of AR in education will be eliminated. The subject of the study is herein described.

\section{Purpose of the Study}

The purpose of the study presented in the paper is to provide a rationale for using AR technology in the learning process at educational institutions to shape digital literacy and digital skills in future teachers.

\section{Research Methods}

A theoretical basis of the study is a comprehensive comparative analysis into the use of digital learning technologies. The issues discussed are based on the analysis of international and Russian studies, as well as regulatory mechanisms stimulating the transition to digital vocational education. In addition, the activities of teachers using digital learning technologies, including AR technology, in higher and secondary vocational education were subjected to scientific reflection.

The following research methods were also used, namely: analysis of scientific, psychological, pedagogical and methodological literature, regulatory documents on the issue under study, analysis of personal pedagogical and research activities of the authors on the development of digital literacy in future teachers and its constituent digital skills.

\section{Findings}

The analysis of literature, practices applied in teaching students as future teachers made it possible to identify a list of digital skills that can be formed using, among other things, AR technology.

The first group is basic functional (core) digital skills, the basic level. It can include the functional use of digital devices (for example, smartphones); scanning textbook pictures (creating application labels); using the Internet (searching for information). The second group is general digital skills, the general level. It can be represented by such skills as processing textbook pictures (to create labels); working with software to create application designs; searching and arranging information about various processes and phenomena. The third group is specialized professional digital skills, the advanced level. It can comprise programming in $\mathrm{C \#}$ language; developing mobile applications using software tools like Unity 3D, Vuforia.

The paper later on shows the possibilities of developing the above groups that comprise digital skills, including those related to AR technology, based on a comparative analysis into the curricula of various areas of HE training and fields of secondary vocational education, implemented at Transbaikal State University (44.03.01 Pedagogical education, profiles - Preschool education, Primary education) and Chita Pedagogical College (SVE fields - 44.02.01 Preschool education (program of advanced training), 44.02.02 Teaching in Primary School (program of advanced training). 
Thus, the basic digital skills, the basic level, are possible to develop within the framework of Informatics and ICT, a compulsory subject in the curricula of training areas 44.03.01, and Informatics, a compulsory subject in the curricula of SVE fields of study 44.02.01, 44.02.02.

The general digital skills, the general level, are possible to develop within the framework of Information and Communication Technologies in Education, a compulsory subject in the curricula of training areas 44.03.01, and Informatics and ICT in Professional Activity, a compulsory subject in the curricula of SVE fields of study 44.02.01, 44.02.02. In addition, the curricula of the analyzed HE training areas and SVE fields of study include some additional disciplines, the content of which allows the development of general digital skills. These are such disciplines as: Methods of Teaching Informatics in Primary School (44.03.01, profile Primary Education, a compulsory part of the academic program), ICT in Professional Activity of Preschool Teacher (44.03.01, profile Preschool Education, a variable part of the academic program), Informatics with Teaching Methods (02.02.02, a variable part of the academic program), Game Technologies in Preschool Education using ICT, Theory and Methodology of Using ICT in Preschool Education (44.02.01, a variable part of the academic program).

That way, both the compulsory and variable parts of the curricula of the above HE training areas and SVE fields of study include the disciplines, the content of which allows the development of digital skills in students as future teachers at the basic and general levels.

For the development of specialized professional digital skills, the advanced level, it is necessary to teach students as future teachers, first of all, programming using various languages, for example, programming in C\# for applying AR technology.

Analyzing the curricula of the direction of training 03.04.05 Pedagogical Education (with two training profiles), profiles Mathematics and Informatics, Informatics and Physics, implemented at Transbaikal State University, showed that the development of specialized professional digital skills, the advanced level, in future teachers is possible within the framework of Computer Software, Programming, WEB-programming Technologies, Web-technologies, Computer Graphics, Computer Architecture, 3D Modeling and Animation, Structure and Organization of Educational Software. The development of digital skills at the advanced level within the framework of the above disciplines is possible, provided that a number of conditions are met, including the availability of appropriate expensive equipment.

Here are some examples of applying various types of AR applications in the educational process in higher education.

Augmented reality has found great application when real objects are replaced with virtual ones (object modeling). This way, studying Computer Architecture can involve, instead of real details, 3D objects of augmented reality. What is more, each student can observe a single computer device, get an idea of its technological structure and features, etc. To conduct these lessons, the teacher must have: ready-made 3D models developed in modeling programs; webcams, AR controllers; software for recognizing markers of augmented reality in digital or analog versions; demonstration equipment (projectors, screens, interactive whiteboards, etc.).

Augmented reality for teaching mathematics can assist in visualizing geometric 3D shapes. Notably, augmented reality provides opportunities such as moving, rotating, scaling 3D models, viewing them from any angle, connecting and disconnecting virtual objects and studying the results (training 
applications). Thus, students studying the sections of mathematics related to stereometry might have great difficulties with representing figures in space and constructing sections, drawing planes. To ensure greater clarity, accessibility and ease of presenting learning material, augmented reality can serve as an optimal solution. Exemplarily, when analyzing a topic, like Polygons, students through a 3D model can view sections using the mobile application with augmented reality Arloon Geometry and can build sections on their own.

All of the above examples demonstrate wide possibilities of using AR technology, showing, though, that this technology cannot exist without relevant technical support. Currently, the use of augmented reality in the learning process is hampered, on the one hand, by an insufficient number of ready-made Russian-language multimedia manuals and applications, on the other hand, by the use of expensive equipment.

The problem of developing Russian-language multimedia manuals and applications can be solved by students themselves, e.g. by creating their own AR objects when they study a specific topic based on specialized software within the above disciplines.

Let us consider an example of the idea implemented with a view to developing the above digital skills, being part of digital literacy, among students as future teachers.

Within network interaction between educational institutions (Transbaikal State University and Chita Pedagogical College), a student of Chita Pedagogical College, field of study 09.02.03 Programming in Computer Systems, having a retraining diploma in Teacher of Informatics, together with a student in the direction of training 44.03.05 Pedagogical Education (with two training profiles), profile Informatics and Physics, developed a mobile application using AR technology Living Physics for a Physics textbook, grade 9, authors A. V. Pyoryshkin, E. M. Gutnik, included in the Federal List of Textbooks. The application was developed using the Unity 3D software, Vuforia and the C\# programming language.

The developed mobile application interacts with images, presented in the physics textbook and received from the camera of a mobile device, and then projects onto the screen, for example, created virtual physical experiments and phenomena. The application contains a set of animated threedimensional visualizations of physical processes and phenomena corresponding to the materials on the pages of the textbook, like mechanical movement of a balloon, demonstration of Newton's second law, free fall of a ball onto the ground from a certain height, etc. Thus, this mobile application gives students an opportunity to learn more about physical processes and phenomena, as well as gain basic knowledge of physics using AR technology in 3D.

During the development of the mobile AR application, the students demonstrated all three groups of digital skills presented in the paper above.

The mobile application with AR was tested in classroom settings for a group of children in the Children's Technopark Quantorium (Center for Children and Youth Technical Creativity of the Transbaikal Territory) in order to familiarize them with AR on the topic Augmented Reality Toolkit. During the lesson, this application was demonstrated, thanks to which the children were able to get to know the features of AR implementation, watching some physical phenomena, such as mechanical movement of a balloon, interaction of moving interlocking bodies, Newton's third law, etc. Talking to the children enabled to conclude that it was of genuine interest for them to work with the mobile application. 


\section{Conclusion}

As can be seen from the above, the range of applications for augmented reality is very wide. It enriches the world around with the latest technology, thus enabling a unique blended interactive experience. However, using AR technology in education can entail some difficulties associated with both content (insufficient number of ready-made developed Russian-language multimedia manuals and applications) and organizational (use of expensive equipment) aspects. More and more teachers, researchers and developers are involved in solving the issue of the effective use of digital technologies, including AR technology, the creation of interactive teaching methods, etc. A number of such techniques grow into interesting and creative projects.

Applying digital learning technology, the teacher should invoke the learning outcomes and determine the level at which basic, general and specialized professional digital skills should be developed in students as future teachers. It is the learning outcomes that will guide the choice of digital technologies and, as a special case, the choice of AR technology.

\section{References}

Abylkasymova, A. E., Kalney, V. A., \& Shishov, S. E. (2019). The turning point in the training of teachers in the context of the development of digital technology. Bull. of the RMAT, 1, 56-61.

Blinov, V. I., Dulinov, M. V., Yesenina, E. U., \& Sergeev, I.S. (2019). The project of the didactic concept of digital vocational education and training. Pero.

Desnenko, S. I., \& Pakhomova, T. E. (2020). Conditions of digitalization of education in aspect of the problem of forming ICT competence of students of pedagogical college as future teachers. Inform. and Ed., 4, 37-45.

Digital Skills Toolkit (2018). ITU. https://www.itu.int/en/ITU-D/DigitalInclusion/Documents/ITU\%20Digital\%20Skills\%20Toolkit.pdf

Petrova, N. P., \& Bondareva, G. A. (2019). Digitalization and digital technologies in education. The world of science, culture, education, 5(78), 353-355.

Tzima, S., Styliaras, G., \& Bassounas, A. (2019). Augmented Reality Applications in Education: Teachers Point of View. Ed. Sci., 9, 99.

UNESCO (2017). Working Group on Education: digital skills for life and work. Broadband Commission for. Sustainable Development, ITU and UNESCO. https://d-russia.ru/wpcontent/uploads/2017/10/Digital-skills-for-life-and-work_259013e.pdf

UNESCO (2019). UNESCO ICT Competency Framework for Teachers. VERSION 3Digital library UNESCO: official site. http://ru.unesco.kz/unesco-ict-competency-framework-for-teachers-version-3

Voronina, Y. V. (2019). The teacher's digital literacy: analysis of the concept and structure. Bull. of the Orenburg State Pedag. Univer., 4(32), 232-245.

Youm, D., Seo, S., \& Kim, J. (2019). Design and development methodologies of Kkongalmon, a location-based augmented reality game using mobile geographic information. J. Image. Video Proc., 1.

Yuen, S., Yaoyuneyong, G., \& Johnson, E. (2011). Augmented reality: An overview and five directions for AR in education. J. of Ed. Technol. Development and Exchange, 1, 119-140.

Zhigalova, O. P., \& Tolstopyatov, A. V. (2019). The use of augmented reality technology in the educational field. Baltic Human. J., 2(27), 43-46. 